\title{
STUDIES IN COATINGS FOR WORKING BODIES OF DEEP-RIPPERS RECOVERED BY PLASMA SURFACING
}

\author{
Vladimir Shakhov ${ }^{1}$, Semjons Ivanovs ${ }^{2}$, Pavel Uchkin ${ }^{1}$, Yuriy Ushakov ${ }^{1}$ \\ ${ }^{1}$ Orenburg State Agrarian University, Russia; \\ ${ }^{2}$ Latvia University of Life Sciences and Technologies, Latvia \\ shahov-v@yandex.ru, semjons@apollo.lv,pu1985@rambler.ru,1u6j1a159@mail.ru
}

\begin{abstract}
Abrasive soil particles affect the working bodies of tillage machines and cause their wear-out, due to which the agrotechnical parameters of soil cultivation are being disturbed. The use of innovative restoration technologies makes it possible to increase the resource of the deep-ripper working bodies. One of such methods is plasma surfacing, which is now widely applied in the above working bodies repair. However, to obtain highquality surfaces, it is necessary to study the process of layer formation and establish optimal modes of the coat application as well as the most efficient materials, among which tungsten carbide is most commonly used. To find out the best performance of the surfacing process, the laboratory studies of samples, having been coated by means of the plasma method, and production tests of the deep-ripper chisels, restored in specified modes, have been carried out. As a result of the experiments conducted, the most expedient parameters of plasma surfacing of the deep-ripper chisels, i.e.: working voltage $-35 \mathrm{~V}$, deposition rate $-4.5 \mathrm{~m} \cdot \mathrm{h}^{-1}$, content of powders in the mixture (tungsten carbide + PG-S27) -50 to $50 \%$ by volume, have been determined. Using these modes, the surface layer with a hardness of about $70 \mathrm{HRC}$ and wear resistance, exceeding that of a new working body up to 5 times, can be obtained. The conducted studies allow us to recommend this method of restoration of the working bodies of deep-rippers for use by enterprises engaged in the repair of tillage equipment.
\end{abstract}

Keywords: plasma surfacing, hardness, wear resistance, chisel, surfacing modes.

\section{Introduction}

It is commonly known, that abrasive particles affect the working bodies of tillage machines, and particularly, deep-rippers during the operations causing their wear-out and forming deviations from the nominal size and correct geometric shape, which are corrected while restoring parts using different methods and technologies.

One of the effective methods of restoration is powder-plasma surfacing [1]. The advantages are a small depth of penetration of the recovered part and the absence of mixing of the weld pool metal [2].

Another distinctive feature of this method of recovery is the possibility to surface refractory composite materials with high hardness and wear resistance [3]. The powders consisting of the component of the matrix (powder based on iron) and tungsten carbide as a reinforcing structure have recently found wide application $[4 ; 5]$.

\section{Methods and materials}

Studies of the restored bits of deep-rippers on hardness and wear resistance of the surfaced feature were carried out, and the chemical composition and microstructure of the surfaced layer were determined in the laboratory of the Technical Service, Department of the Orenburg State Agrarian University [6;7].

Powder material surfacing was carried out with the plasma surfacing unit, developed at the Technical Service Department (Fig. 1) for samples $110 \times 40 \mathrm{~mm}$ in size (Fig. 2), made of $65 \mathrm{G}$ grade steel (used in the manufacturing of deep-rippers chisels).

As a result of the analysis of the physical and mathematical model of powder-plasma surfacing with tungsten carbide content [3], it was revealed that in this process, the parameters that mostly affected the quality of the surfaced layer, determined by the hardness of the coating, were: composition of the surfaced powder (in our case, the percentage of tungsten carbide), the operating voltage between the nozzle of the plasma torch and the part, and the surfacing rate. The experiments were carried out at different parameters in accordance with the conditions of three-factor modeling of experiments. 175 samples were surfaced in all combinations of the operating parameters.

The surfacing material was a composition of two powders: PG-C27 "Sormayt" and VK-8 (92\% $\mathrm{WC}+8 \% \mathrm{Co}$ ). The optimal ratio of the volumes of these powders in the mixture had to be established during the experiments. It is known that the content of the carbide component should be in the range 
from 30 to $60 \%$. If its amount is less than $30 \%$, the matrix will wear out faster than the hardening phase (WC), and tungsten carbide will subsequently crumble. If the amount is more than $60 \%$, the quality of the carbide adhesion in the matrix will be insufficient, due to the large number of grains and it will begin to crumble immediately during the operation, rather than wear. Accordingly, the powder with 30 to $60 \%$ tungsten carbide content and5 \%increments was used in the experiments.

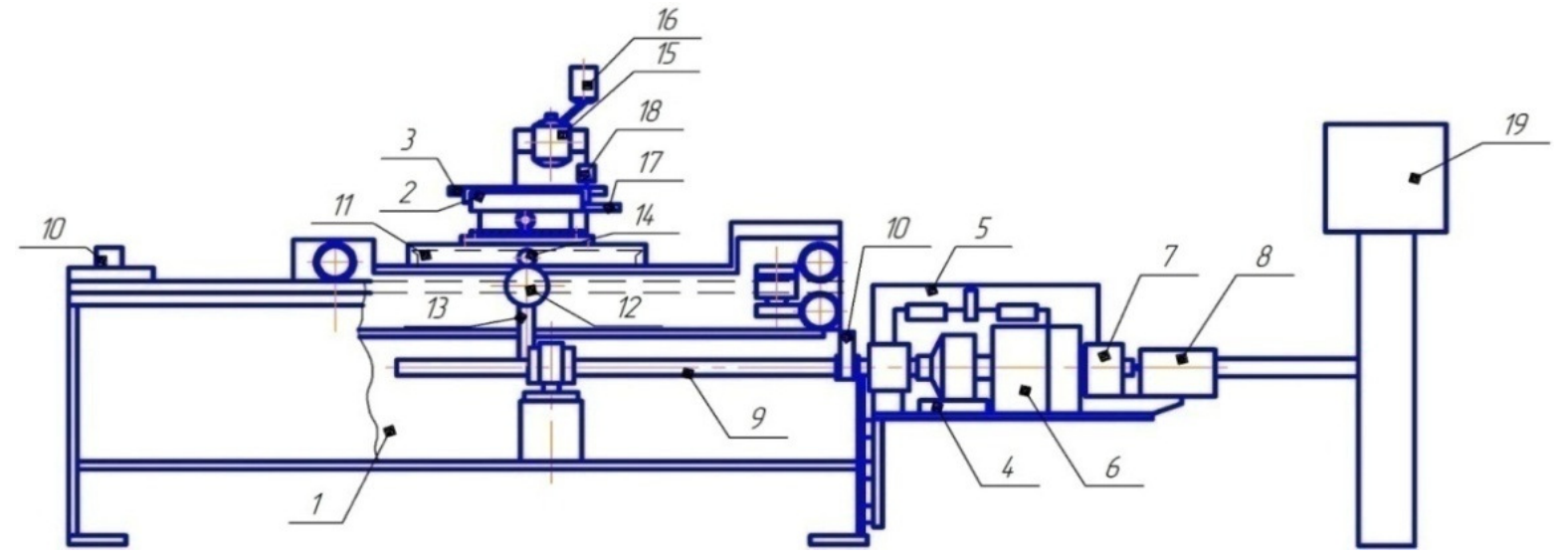

Fig. 1. Plasmasurfacing unit: 1 - body; 2 - turning vise; 3 - chisel; 4 - longitudinal slide drive; 5 - electric motor; 6 - gear unit; 7 - belt drive; 8 - tach-generator; 9,14 - lead screw nut;

10 - limit switch; 11 - cross motion slide drive; 12 - electric coupling with cog wheel; 13 - idler gear;

15 - plasmotron; 16 - powder feeder; 17 - pyrometer; 18 - thickness gage; 19 - control module

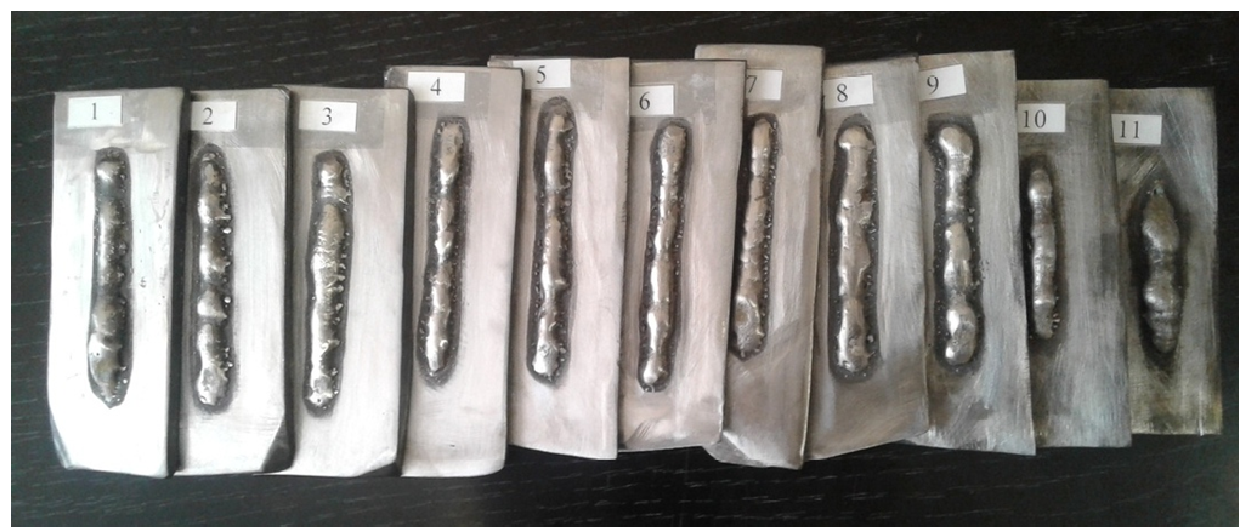

Fig. 2.Samples surfaced by plasma surfacing at various modes

The operating voltage varied from 25 to $45 \mathrm{~V}$, as at these values the value of the current is regulated quite widely from 140 to $260 \mathrm{~A}$ at the same resistance.

Our studies showed that the current strength in plasma surfacing depends on the applied material and is determined by the following expression [8]

$$
I=\frac{1.16 V_{\mu} \rho_{\text {мem }} h_{n л}}{U k_{n o p}},
$$

where $V_{H}$ - surfacing rate, $\mathrm{m} \cdot \mathrm{h}^{-1}$;

$\rho_{\text {мem }}$ - parent metal density, $\mathrm{g} \cdot \mathrm{cm}^{-3}$;

$h_{n л}$ - part's parent metal specific enthalpy, $\mathrm{J} \cdot \mathrm{g}^{-1}$;

$U-$ arcing voltage, $\mathrm{V}$;

$k_{\text {nop }}$ - coefficient considering surfacing powder composition, dependent on:

$$
k_{n o p}=7.57 \frac{\rho^{2}}{\rho_{M}},
$$

where $\rho$-surfacing powder density, $\mathrm{g} \cdot \mathrm{cm}^{-3}$;

$\rho_{\mathrm{M}}-$ surfaced metal density, $\mathrm{g} \cdot \mathrm{cm}^{-3}$. 
In order to establish the optimal ratio of the powder volume and to determine the values of the $k_{\text {nop }}$ coefficient, it was necessary to weigh [6] according to the following scheme: weighing of $10 \mathrm{~cm}^{3}$ of the powder mixture, the sample was weighed before and after surfacing, while the geometric parameters of the seam were measured taking into account the penetration depth equal to $h_{\text {npon }}=0.5 \mathrm{~mm}$. Then, according to the known formula [6], the density of materials and the value of the efficiency were calculated.

The speed of the surfacing process varied in the range from 3.5 to $5.5 \mathrm{~m} / \mathrm{h}$, as at these values the surfacing powder was supplied to the surfacing zone without unnecessary resistance.

The chemical analysis was made by the optical emission analyzer of metals and alloys PMIMASTERUVR in the "spark" mode[6].

The microstructure of the obtained seam was tested on an inverted metallographic microscope MICROMED MET on prepared micro-sections (Fig. 3).

According to GOST 8.335-2004,hardness measurements were carried out by the device "TEMP2" [6] after surfacing.

After laboratory studies, for their verification, in order to check them, the chisels of the deepripper Gaspardo Artiglio were restored by plasma surfacing under the established optimal conditions (Fig. 4).

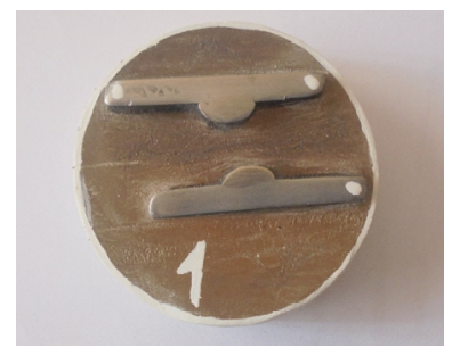

Fig. 3. Prepared micro-sections surfaced by plasma powder method with different content of tungsten carbide and pressed into epoxy resin

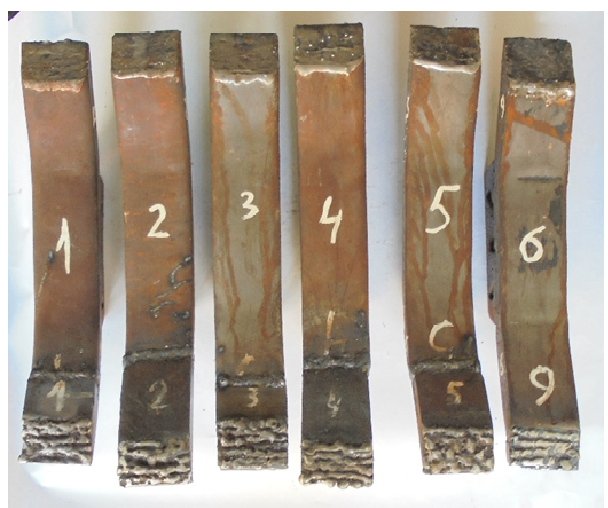

Fig. 4. Restored chisels of Gaspardo Artiglio deep-ripper

\section{Results and discussions}

After surfacing, various parameters of the obtained samples (Fig. 2) were studied. First of all, the values of the $k_{\text {nop }}$ coefficient considering the composition of the surfacing powder were determined and the graph of its values depending on the content of tungsten carbide in the powder mixture was plotted (Fig. 5).

Then the chemical analysis of the applied coating was carried out and the dependence of the impurity content on the current strength during surfacing was built (Fig. 6), which shows that the higher the current, the lower the content of impurities (oxygen, nitrogen, etc.). This is due to the fact that with increasing the current strength there was a greater burnout of impurities due to the greater heat released during surfacing. The optimal value of the impurity content was considered to be less than $1 \%$ and it corresponded to the value of the current equal to about 190-200A, at which the voltage was $35 \mathrm{~V}$. 


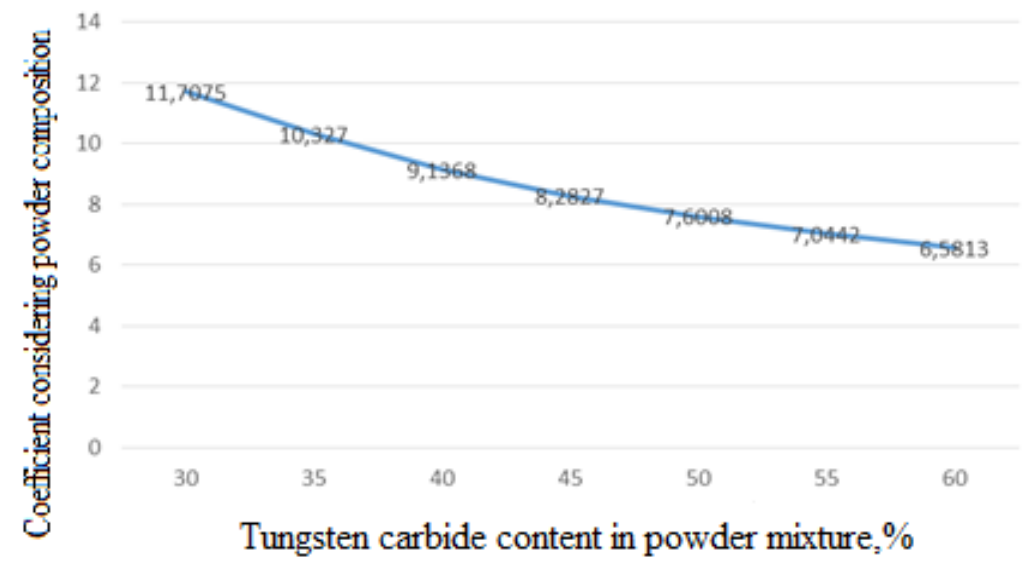

Fig. 5. Dependenceof $k_{n o p}$ coefficient considering powder composition and tungsten carbide content in mixture with PG-S27 "Sormayt" powder

Subsequently, the microstructure of the obtained coating was studied. It was found in the conducted study [9] that the best structure in shock-abrasive friction was the ledeburitic structure of the dendritic-cellular type. That was the reason for choosing PG-C27 powder with a high carbon content $(4 \%)$ as the mixture matrix, as it gave such a structure. As a result of the experiments, the optimal volume amount of tungsten carbide in the mixture was found to be $50 \%$. The content above this value lead to oversaturation and in the subsequent layer during operation would simply be destroyed - crumble, but not wear out.

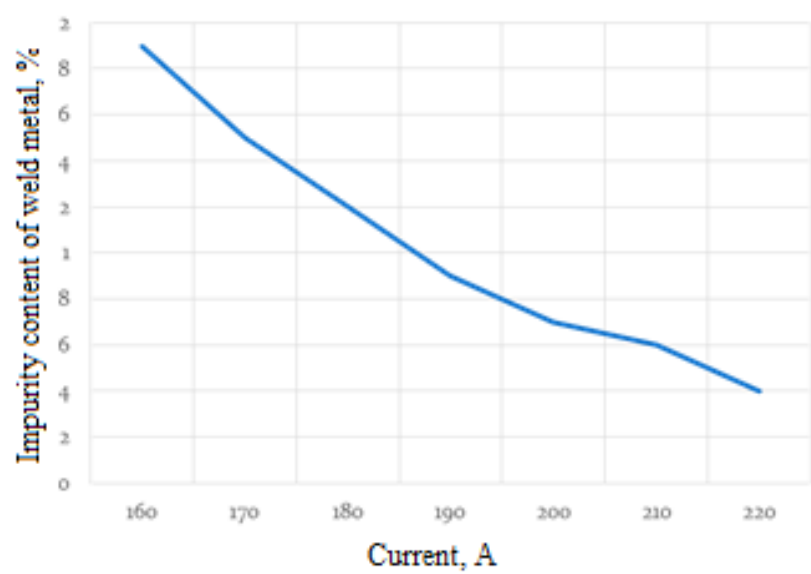

Fig. 6. Dependence of concentration of impurities in deposited coating on current
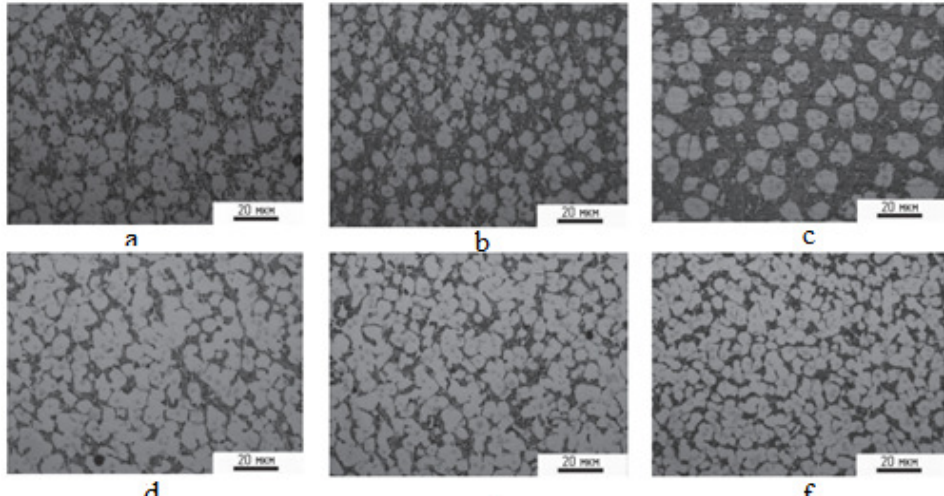

Fig. 7. Microstructure of surfaced layer depending on different tungsten carbide content in mixture: $\mathrm{a}-30 \% ; \mathrm{b}-35 \% ; \mathrm{c}-40 \% ; \mathrm{d}-45 \% \mathrm{e}-50 \% ; \mathrm{f}-55 \%$

Then the hardness measurements of the surfaced layer were carried out and the experimental data on the basis of the experimental results were processed. Based on the regression equation (3) to 
determine the optimal deposition regime during the recovery of the deep-ripper chisel (Fig. 8-10) the response surfaces were constructed.

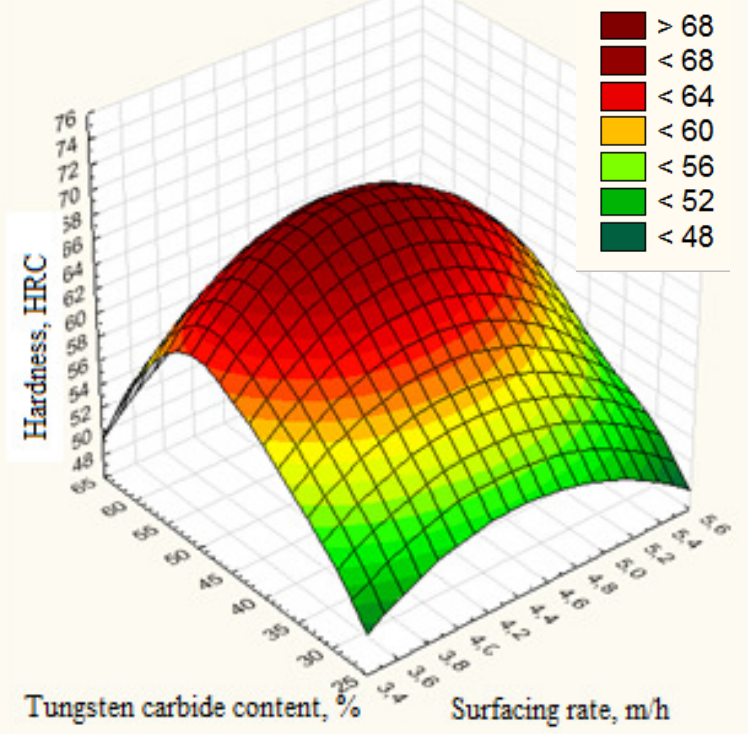

Fig. 8. Dependence of surfaced layer hardness on tungsten carbide content in powder mixture and surfacing rate

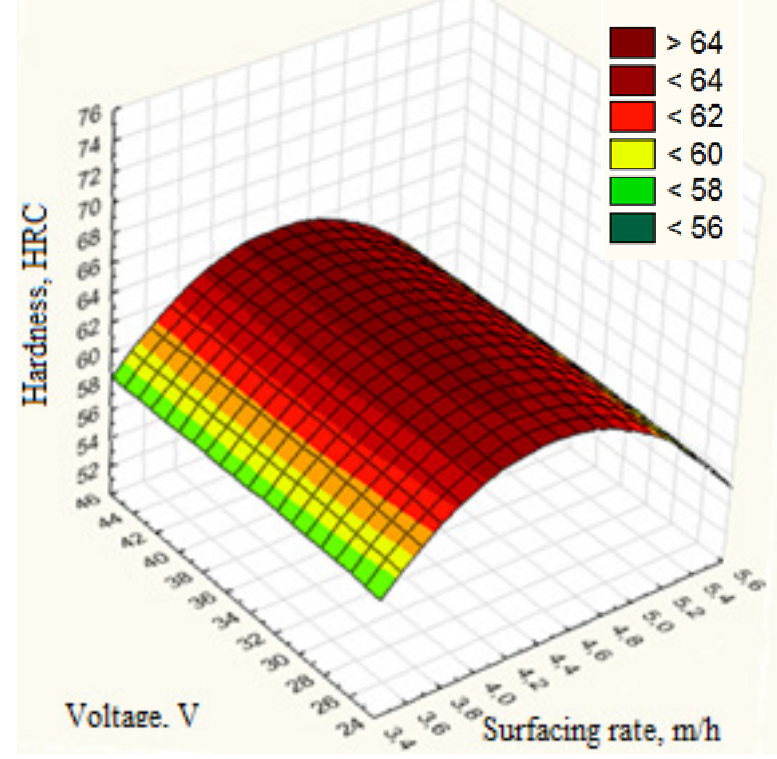

Fig. 9. Dependence of surfaced layer hardness on arcing voltage and surfacing rate

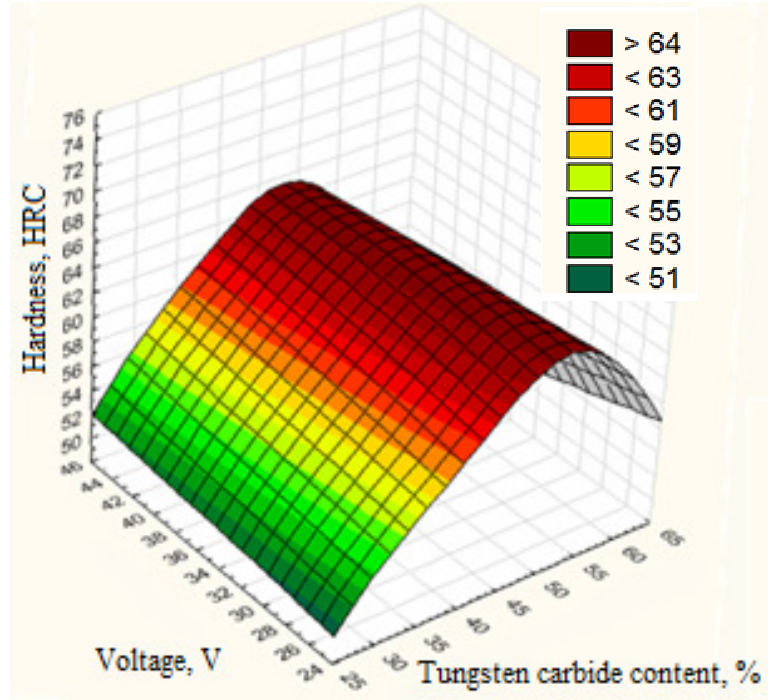

Fig. 10. Dependence of surfaced layer hardness on arcing voltage and tungsten carbide content in powder mixture

In the course of the analysis of the response surfaces, the following optimal operating parameters of plasma surfacing of wear-resistant coatings were determined:

- $\quad$ surfacing rate $-4.5 \mathrm{~m} \cdot \mathrm{h}^{-1}$;

- tungsten carbide content in the powder mixture $-50 \%$;

- $\operatorname{arcing}$ voltage $-35 \mathrm{~V}$.

They at the hardness of the surfaced layer ranged from 52.7 to $73.2 \mathrm{HRC}$. The highest hardness value corresponded to the optimal regime parameters.

$$
y=-144.408+54.170 x_{1}+3.418 x_{2}+0.872 x_{3}-0.027 x_{1} x_{2}-0.055 x_{1} x_{3}-0.016 x_{2} x_{3},
$$

where $x_{1}, x_{2}, x_{3}$ - variable factors in coded form, corresponding to the deposition rate $\left(V_{H}\right)$, 
content of tungsten carbide in the powder $(W)$, voltage between the plasmotron and the part $(U)$.

At a later stage Gaspardo Artiglio deep-ripper chisels were surfacedat the optimal modes: bit No.1 $V_{H}=4.5 \mathrm{~m} \cdot \mathrm{h}^{-1}, W=45 \%, U=45 \mathrm{~V}$; chisel No.2 $V_{H}=4.5 \mathrm{~m} \cdot \mathrm{h}^{-1}, W=50 \%, U=25 \mathrm{~V}$; chisel No.3 $V_{H}=4.5 \mathrm{~m} \cdot \mathrm{h}^{-1}, W=50 \%, U=30 \mathrm{~V}$; chisel No.4 $V_{H}=4.5 \mathrm{~m} \cdot \mathrm{h}^{-1}, W=50 \%, U=35 \mathrm{~V}$; chisel No.5 $V_{H}=4.5 \mathrm{~m} \cdot \mathrm{h}^{-1}, W=50 \%, U=40 \mathrm{~V}$; chisel No. $6 V_{H}=4.5 \mathrm{~m} \cdot \mathrm{h}^{-1}, W=50 \%, U=45 \mathrm{~V}$ and the seventh chisel was installed new to compare.

It was found in the process of testing that the restored bits have up to 5 times longer life compared to the new bit (Fig. 11). At the same time, the least wear is observed in the chisel No.4 surfaced at optimal conditions (Fig. 8).

\section{Conclusions}

According to the results of the conducted studies of restoration of deep-ripper chisels plasma surfacing optimal modes of the coating process $V_{H}=4.5 \mathrm{~m} \cdot \mathrm{h}^{-1}, W=50 \%, G=35 \mathrm{~V}$ were established. When using these parameters, a layer with a hardness of $73.2 \mathrm{HRC}$, the least amount of impurities, less than $1 \%$, a ledeburitic dendritic-cellular structure was formed, the wear resistance of which is 5 times higher than the wear resistance of the new serial chiselmaterial.

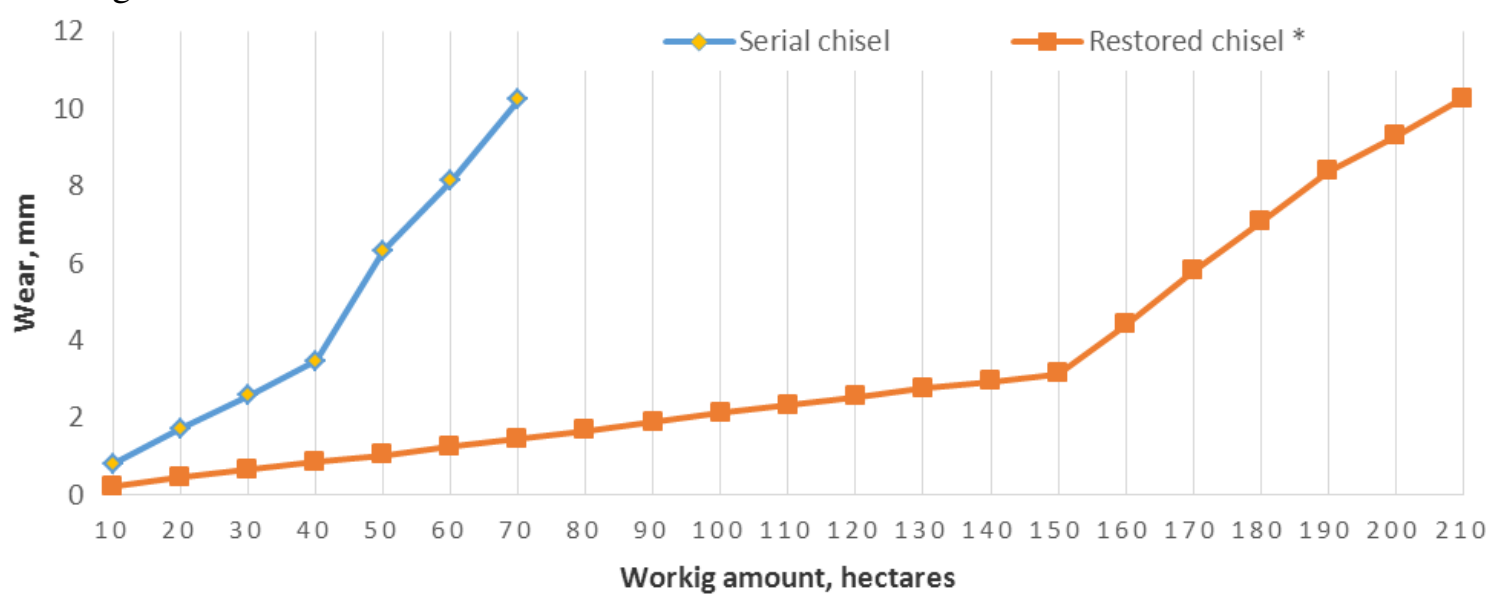

Fig. 11. Results of wear of serial and restored chisels according to performance tests: $*$ - average value of test results 6 chisels

\section{References}

[1] Lyalyakin V.P., Mikhalchenkov A.M., Solovev R.Y. Effect of welding methods on the magnitude of residual stresses in welding up cracks in grey cast iron casing components Welding International, vol. 32 No. 1, 2018. - T. 32. pp. 67-71.

[2] Foleg A. Abrasive wear of cultivation equipment by soil. Soil and Water,vol. 12, No. 2, 1984.

[3] Latypov R.A., Latypova G.R., Ageev E.V., Altukhov A.Y., Ageeva E.V. Properties of the coatings fabricated by plasma-jet hard-facing by dispersed mechanical engineering wastes. Russian metallurgy (Metally),vol. 2018, No. 6, 2018, pp. 573-575

[4] Kravchenko I.N., Kolomeychenko A.V., Pupavtsev I.E., Solovev R.Y., Baranov Y.N. Thermal efficiency of plasma-jet deposition of powder materials. Welding International, vol. 32, No. 1, 2018, pp. 54-61.

[5] Svobodová J., Kraus P., Müller M., Lebedev A., Yurov A., Lebedev P. Influence of cutting fluid on abrasive-free ultrasonic finishing of aluminium alloy. Manufacturing Technology, vol. 15, No. 4, 2015, pp. 710-714.

[6] Shakov V.A., Uchkin P.G., Glushkov I.N., Ognev I.I. The results of laboratory tests of plasma surfaced coatings. News of the International Academy of Agrarian Education, vol.40, 2018, pp. 30-33.

[7] Knyazkov K.V. Development of the technology for modifying wear-resistant coatings of Ni-CrB-Si-Fe/WC system in the process of plasma-powder surfacing.Thesis work. Barnaul, 2015, $125 \mathrm{p}$. 